\title{
Coverage analysis of Scopus: A metric approach
}

\author{
FÉLIX DE MOYA-ANEGÓN, ZAIDA CHINCHILLA-RODRÍGUEZ, \\ BENJAMÍN VARGAS-QUESADA, ELENA CORERA-ÁlVAREZ, \\ Francisco JosÉ MUÑOZ-FERnÁNDEZ, ANTONIO GONZÁLEZ-MOLINA, \\ VICTOR HERRERO-SOLANA
}

SCIMAGO Research Group, University of Granada, Library and Information Science Faculty, Granada (Spain)

\begin{abstract}
Our aim is to compare the coverage of the Scopus database with that of Ulrich, to determine just how homogenous it is in the academic world. The variables taken into account were subject distribution, geographical distribution, distribution by publishers and the language of publication. The analysis of the coverage of a product of this nature should be done in relation to an accepted model, the optimal choice being Ulrich's Directory, considered the international point of reference for the most comprehensive information on journals published throughout the world. The results described here allow us to draw a profile of Scopus in terms of its coverage by areas - geographic and thematic - and the significance of peer-review in its publications. Both these aspects are highly pragmatic considerations for information retrieval, the evaluation of research, and the design of policies for the use of scientific databases in scientific promotion.
\end{abstract}

\section{Introduction}

To date the Thomson Scientific citation databases have stood out from the rest on two grounds: their multidisciplinarity and their international coverage. Comprising approximately 8,700 scientific journals in their Web of Science version, they have become the main tool for information retrieval and for science evaluation studies worldwide. Secondly, particular characteristics concerning information related to

Received January 22, 2007

Address for correspondence:

FÉLIX MOYA-ANEGÓN

University of Granada, Library and Information Science Faculty

Campus Cartuja, 18071 Granada, Spain

E-mail: felix@ugr.es

$0138-9130 /$ US $\$ 20.00$

Copyright (C) 2007 Akadémiai Kiadó, Budapest

All rights reserved 
research quality and its impact in the scientific community have led the governments of some countries to show specific interest in this tool as a means of evaluation, requiring researchers to have published in journals included in these databases - especially in those of a high impact factor - and covered by the Journal Citation Report (JCR).

Yet recently (November 2004) an alternative tool has appeared on the information market: Scopus, created by Elsevier. It is now the largest database for multidisciplinary scientific literature existing on the market. This navigation tool is updated daily and includes summaries and references cited since 1966, from more than 14,000 journals (16,000 if non-active journals are included) and from all areas of knowledge. Scopus offers a complete package of services aside from its bibliographic contents. Its interface, for instance, was designed to provide a global view of results, enabling researchers to quickly identify both what is relevant to them in particular along with the current overall trends in their fields of study. In searching for citations and references, Scopus allows connections by disciplines; it achieves high levels of precision when matching references to summaries; it offers links to the full text, to Open Access sources and library catalogues, to exclusively electronic publications and to cited articles from the results, summary and references lists; and researchers can apply for new contents, sources or document types, even modifying the configurations and personalising their choices. The literature already includes research studies that analyse the characteristics of this product (JACSO, 2004; CODINA, 2005; LAGUARDIA, 2005).

Meanwhile, comparative studies are appearing on the horizon as well, looking at the coverage, interface accessibility, usability, price, etc., of Scopus versus ISI (DEIS \& GOODMAN, 2004; JACSO, 2004; LAGUARDIA, 2005). It would appear that Scopus and ISI-WOS have entered head-on competition (PICKERING, 2004) and any comparison of the two products calls for utmost care as well as methodological consistency. Previous authors have compared Ulrich with ISI databases: BRAUN et al. (2000) with SCI, and ARCHAMBAULT et al. (2005) with SSCI and A\&H. Ulrich's Directory is clearly a worldwide point of reference for the most comprehensive information on journals published the world over.

However, the aim of this study is not to make a comparison of the two databases (ISI and Scopus), but rather apply similar methodology to look closer at Scopus, examining just how balanced the coverage that it offers is, with the Ulrich directory as the "gold standard" of reference. Scopus's coverage with respect to Ulrich is evaluated by taking a series of variables into account such as journal subject distribution, geographical distribution, distribution by publishers, the language of publication, and whether peer-reviewed or not. 


\section{Material and methodology}

The two journal collections under comparison are Scopus and the Core version of Ulrich's Directory. At present UlrichsWeb.com is the directory covering the greatest number of journal publications, with over 230,000 titles from approximately 138,000 publishers.

The Serials Analysis System facilitates comparisons between subject categories, publishers, and the language and country of publication, all done working from a base collection of journals both in Ulrich's Universe, which includes all titles (234,173 as of October 2005) and in Ulrich's Core, which contains journals of an academic nature and peer-reviewed $(60,859$ titles in October 2005). Using the bibliographic information from each journal, the following aspects can be determined: which journals are peerreviewed, their availability in databases, subscription characteristics, inclusion in the JCR lists, etc. We target two of these areas: the Scopus collection will be analysed and compared with Ulrich's Core in relation to the number of subject areas covered, number of journals in each area (geographic and thematic), and type of review process (peerreviewed or not).

A key comparison of ISI databases with those of Ulrich's Directory was published in the Homage to Garfield in 2000. Our study differs both in point of reference and in subject matter. Whereas the previous authors considered only Science and Technology according to Ulrich CD (BRAUN et al., 2000), our analysis uses the online version of Ulrich's Core (www.ulrichsweb.com) to include all subject categories from the academic world, not just the basic and experimental sciences of Ulrich's Science \& Technology (U-S\&T). Also, he applied two other conditions concerning journal selection: titles which do not have an ISSN code, and those containing a book, abstract, monograph, etc., in the title were not excluded. In this study matching is done with all the ISSN's of both collections.

Assuming that Ulrich's Periodicals Directory represents the worldwide journal collection, our aim is to determine to what extent it resembles the Scopus collection. Two similarity measures are used to establish correlations between the distributions of journals for the two separate collections. On the one hand, the determination coefficient ( $\mathrm{R}$ squared value) is calculated using the tendency lines of the distribution graphs, which indicate the degree to which estimated and real values correspond. Then, in order to corroborate this similarity, the Pearson correlation coefficient is applied, as previous authors have done (BRAUN et al., 2000). 


\section{Results}

Scopus has a total of 16,658 titles in June 2005, of which just 13,832 initially correspond to the ISSN's in Ulrich's Directory. This mismatch is explained by the data shown in Table 1.

Table 1. Scopus collection characteristics

\begin{tabular}{lrr}
\hline ISSN Scopus & \multicolumn{1}{c}{ Titles } & \multicolumn{1}{c}{$\%$} \\
\hline Matching Ulrich's Universe & 12996 & 78.02 \\
Matching Ulrich's Core & 11529 & 69.21 \\
Title History ISSN & 433 & 2.6 \\
Incomplete Serial Record & 1 & 0.01 \\
Invalid ISSN & 1 & 0.01 \\
ISSN Non-Match & 214 & 1.28 \\
Not active & 1 & 0.01 \\
Mergers and Acquisitions & 37 & 0.22 \\
Ceased & 146 & 0.88 \\
Suspended & 9 & 0.05 \\
ISSN SCOPUS in ULRICHSWEB & 13838 & 83.07 \\
Not ISSN/ISBN & 1386 & 8.32 \\
ISBN & 1232 & 7.4 \\
Repetition & 202 & 1.21 \\
\hline Total Scopus & 16658 & 100 \\
\hline
\end{tabular}

Table 2 shows a general comparison of the main areas recorded in the Universe Version of Ulrich's Web; it includes all titles, as does the Core version (though the latter includes only peer-reviewed titles).

Table 2. Scopus vs. Ulrich's Universe / Ulrich's Core comparison

\begin{tabular}{llrrrr}
\hline Ulrich's Web & SCOPUS & ULRICH & Percentage & $\begin{array}{c}\text { Ulrich's Universe } \\
\text { titles library does } \\
\text { not hold }\end{array}$ \\
& & & & & $\begin{array}{r}221,177 \\
\text { Titles }\end{array}$ \\
& Universe & 12,996 & 234,173 & $5.55 \%$ & 49,330 \\
\hline & Core & 11,529 & 60,859 & $18.94 \%$ & 184,080 \\
& Universe & 12,996 & 197,076 & $6.59 \%$ & 44,998 \\
\hline Refeered & Core & 11,529 & 56,527 & $20.40 \%$ & 19,957 \\
& Universe & 9,615 & 29,572 & $32.51 \%$ & 19,957 \\
\hline Abstracted/Indexed & Core & 9,615 & 29,572 & $32.51 \%$ & 61,111 \\
& Universe & 12,597 & 73,708 & $17.09 \%$ & 29,756 \\
\hline Electronic Journal & Core & 11,273 & 41,049 & $27.48 \%$ & 46,026 \\
& Universe & 10,189 & 56,215 & $18.13 \%$ & 19,774 \\
\hline Magazines for Libraries & Core & 9,535 & 29,309 & $32.53 \%$ & 8,934 \\
& Universe & 2,712 & 11,646 & $23.29 \%$ & 4,857 \\
\hline
\end{tabular}


Scopus matches $5.55 \%$ of the journal titles in relation to Ulrich's Universe version. These represent, in turn, $6.59 \%$ of titles that match and of those being analysed; $32.51 \%$ of these are peer-reviewed, $17.09 \%$ are indexed in databases, and $18.13 \%$ are electronic journals.

In relation to the Core version, Scopus represents $18.94 \%$ of the Ulrich collection and comparisons are carried out starting from $20.40 \%$ of the matching journals. Out of this percentage, $32.51 \%$ are peer-reviewed, $27.48 \%$ are available on data bases, $32.53 \%$ are electronic journals. Altogether, $62.22 \%$ are listed in the JCR. These are the values that will be used to establish the threshold; the variables studied will be evaluated as above or below this average value, that is, over or under-represented.

\section{Subject distribution}

As a result of the matching process with the Scopus collection, subject distribution in Ulrich's Core was seen to divide knowledge into 151 categories, while Scopus has titles in 120 of them. This means that its subject coverage compared to the worldwide point of reference is $79.47 \%$, taking into account the 2,820 titles made reference to above (Table 1). Figure 1 shows the subject distribution of the two journal collections from a dual perspective.

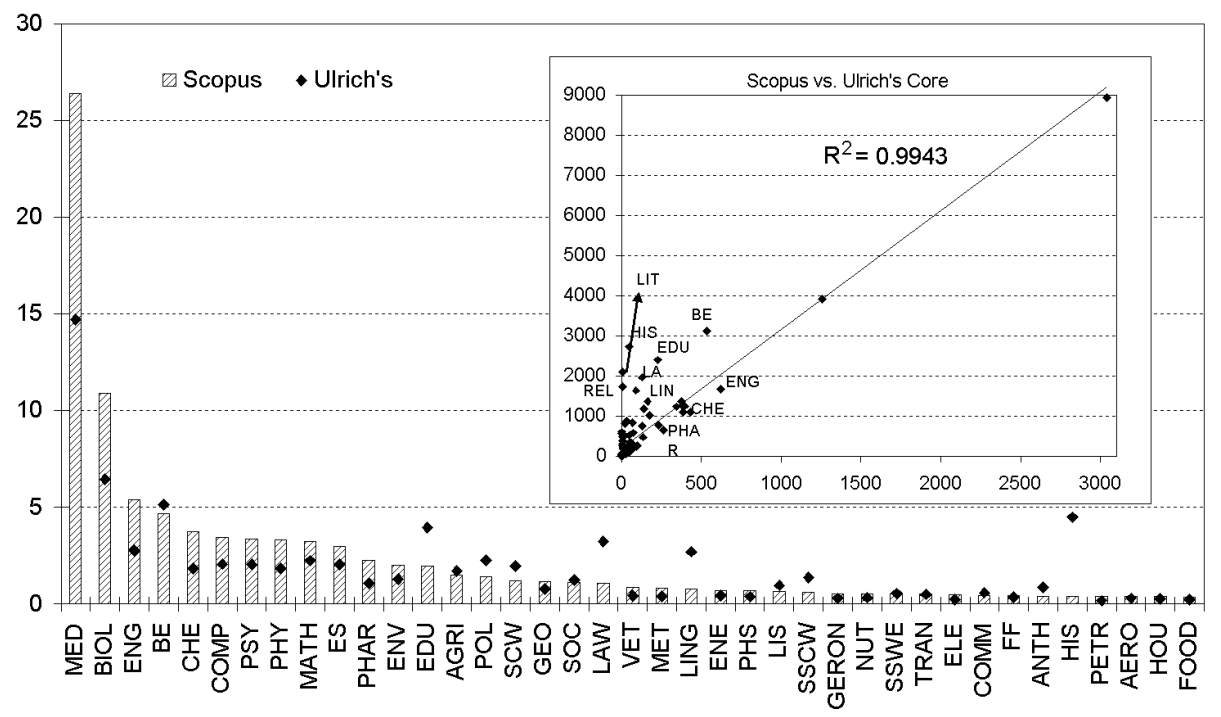

Figure 1. Journal distribution by subject areas - Ulrich's Core 
To the left, the percentual distribution is shown, with only the categories that contain at least 10 journals (representing $98.43 \%$ of the collection) included. The columns show the number of titles in each category in Scopus in descending order, while the points show the Ulrich Core corresponding values. To the right, the overall distribution between the two collections is shown taking all the categories into account (including those with less than 10 journals) and indicating which are furthest away from the average (above or below the line of regression). The squared $\mathrm{R}$ value reflects the similarity of the distribution on the whole.

In Ulrich's Core, $47.5 \%$ of all the categories also represented in Scopus pertain to Medicine, Basic Sciences and Technology. These account for $77.46 \%$ of the total journals. In turn, $34.17 \%$ of the categories belong to Social Sciences, with $19.39 \%$ of the collection's journals, and the rest are from Humanities. As can be seen, the categories showing disparity are mainly in Social Sciences and Humanities. This is shown in Jacso's work (Figure 2) and in the information provided by Scopus on its website.

In Table 3 (and the following), categories with at least ten titles are shown, with 5 columns of the percentage distribution in relation to Ulrich's Core. They provide information on the Scopus collection (\% S/SC); the Ulrich collection (\% U/UC); the percentage of Scopus titles in relation to Ulrich in descending order $(\% \mathrm{~S} / \mathrm{UC})$; and the Scopus refereed journals in relation to Ulrich (Ref/UC).

To assess the balance of international coverage, and bearing in mind that the percentage of Scopus journals in relation to Ulrich Core is $20.40 \%$, this value can be adopted as the threshold point of average representation (hence, categories with higher values are the best represented). As seen in Table 3, 52\% are over-represented in terms of coverage and $62 \%$ are above the threshold of the peer-reviewed variable. For the total categories with journals, $44 \%$ are over-represented. Most of these are from the sciences $(81.13 \%)$, and $54 \%$ have a higher percentage than the average for refereed journals $(32.51 \%)$ of the whole collection. The determination coefficient in this case is 0.68 and the Pearson coefficient is 0.81 .

In order to find the degree of similarity, we applied the Pearson correlation coefficient and obtained a value of 0.9 . This reflects the fact that in various categories there are many more journals than in Scopus, as illustrated in Figure 1. By isolating these cases, we see they are mostly from the Humanities and the Social Sciences (probably non-academic). In terms of the determination coefficient, Figure 1 is very illustrative: we can say that Scopus generally has quite a homogenous global representation in all areas except Arts and Humanities. This has been pointed out in previous studies (DEIS \& GOODMAN, 2004) and can be seen on Scopus's own website, where it describes its subject coverage. 
F. DE MOYA-ANEGÓN et al.: Coverage analysis of Scopus

Table 3. Subject ranking according to the percentage of Scopus journals in Ulrich's Core

\begin{tabular}{|c|c|c|c|c|c|}
\hline Abr. & Ulrich's subject & $\%$ Scopus & $\%$ Ulrich & $\% \mathrm{~S} / \mathrm{U}$ & $\% \operatorname{Ref} \mathrm{S} / \mathrm{U}$ \\
\hline PLAS & Plastics & 0.23 & 0.09 & 45.61 & 52.78 \\
\hline PETR & Petroleum and gas & 0.40 & 0.17 & 43.81 & 55.56 \\
\hline TIF & Textile industries and fabrics & 0.21 & 0.09 & 42.11 & 53.85 \\
\hline PHAR & Pharmacy and pharmacology & 2.26 & 1.07 & 40.09 & 50.00 \\
\hline MET & Metallurgy & 0.82 & 0.40 & 39.17 & 48.84 \\
\hline $\mathrm{CHE}$ & Chemistry & 3.74 & 1.83 & 38.86 & 48.20 \\
\hline ELE & Electronics & 0.49 & 0.24 & 38.10 & 44.44 \\
\hline ENG & Engineering & 5.40 & 2.77 & 37.06 & 50.41 \\
\hline DAA & Drug abuse and alcoholism & 0.32 & 0.16 & 37.00 & 50.75 \\
\hline VET & Veterinary science & 0.84 & 0.44 & 36.47 & 49.73 \\
\hline PHY & Physics & 3.33 & 1.83 & 34.56 & 45.62 \\
\hline PHS & Public health and safety & 0.69 & 0.38 & 34.20 & 45.83 \\
\hline MED & Medical sciences & 26.37 & 14.70 & 34.08 & 44.77 \\
\hline GERON & Gerontology and geriatrics & 0.53 & 0.30 & 33.70 & 48.25 \\
\hline BIOL & Biology & 10.90 & 6.45 & 32.11 & 42.92 \\
\hline COMP & Computers & 3.44 & 2.07 & 31.66 & 40.40 \\
\hline INS & Instruments & 0.10 & 0.06 & 31.43 & 47.62 \\
\hline PSY & Psychology & 3.35 & 2.04 & 31.18 & 43.47 \\
\hline PAL & Paleontology & 0.31 & 0.19 & 31.03 & 51.56 \\
\hline STA & Statistics & 0.34 & 0.21 & 30.95 & 50.68 \\
\hline NUT & Nutrition and dietetics & 0.53 & 0.33 & 30.20 & 40.74 \\
\hline ENE & Energy & 0.69 & 0.44 & 29.70 & 46.46 \\
\hline ENV & Environmental studies & 2.02 & 1.29 & 29.64 & 44.47 \\
\hline WR & Water resources & 0.29 & 0.19 & 29.31 & 49.15 \\
\hline FOOD & Food and food industries & 0.36 & 0.24 & 29.17 & 44.19 \\
\hline MMI & Mines and mining industry & 0.29 & 0.20 & 28.57 & 40.00 \\
\hline ES & Earth sciences & 2.99 & 2.04 & 27.89 & 41.55 \\
\hline GEO & Geography & 1.15 & 0.79 & 27.82 & 42.13 \\
\hline MATH & Mathematics & 3.24 & 2.25 & 27.40 & 37.02 \\
\hline CGP & Ceramics, glass and pottery & 0.14 & 0.10 & 26.23 & 48.28 \\
\hline $\mathrm{HOU}$ & Housing and urban planning & 0.37 & 0.27 & 26.06 & 43.68 \\
\hline $\mathrm{AM}$ & Alternative medicine & 0.20 & 0.15 & 25.84 & 26.92 \\
\hline OHS & Occupational health and safety & 0.22 & 0.16 & 25.00 & 40.74 \\
\hline AERO & Aeronautics and space flight & 0.38 & 0.30 & 23.91 & 39.19 \\
\hline METE & Meteorology & 0.29 & 0.24 & 23.61 & 39.47 \\
\hline $\mathrm{FF}$ & Forests and forestry & 0.43 & 0.37 & 22.32 & 41.00 \\
\hline $\mathrm{FF}$ & Fish and fisheries & 0.24 & 0.21 & 21.54 & 37.50 \\
\hline TRAN & Transportation & 0.50 & 0.50 & 19.21 & 36.07 \\
\hline HAN & Handicapped & 0.14 & 0.14 & 19.05 & 32.50 \\
\hline HFA & Health facilities and administration & 0.17 & 0.17 & 18.87 & 34.00 \\
\hline CRIM & Criminology and law enforcement & 0.33 & 0.34 & 18.63 & 33.71 \\
\hline BUI & Building and construction & 0.17 & 0.18 & 18.35 & 40.91 \\
\hline SSWE & Social services and welfare & 0.52 & 0.54 & 18.24 & 29.41 \\
\hline $\mathrm{BE}$ & Business and economics & 4.65 & 5.13 & 17.20 & 28.36 \\
\hline PS & Population studies & 0.22 & 0.24 & 17.01 & 36.84 \\
\hline ASTRO & Astronomy & 0.29 & 0.33 & 16.92 & 36.56 \\
\hline AGRI & Agriculture & 1.50 & 1.70 & 16.80 & 32.83 \\
\hline SOC & Sociology & 1.11 & 1.26 & 16.80 & 30.63 \\
\hline
\end{tabular}


F. DE MOYA-ANEGÓN et al.: Coverage analysis of Scopus

Table 3. (cont.)

\begin{tabular}{llcccc}
\hline Abr. & \multicolumn{1}{c}{ Ulrich's subject } & \%Scopus & \% Ulrich & \%S/U & \% Ref S/U \\
\hline TCW & Technology: comprehensive works & 0.28 & 0.35 & 15.09 & 23.60 \\
CYABOUT & Children and youth_about & 0.19 & 0.27 & 13.33 & 26.56 \\
LIS & Library and information sciences & 0.64 & 0.96 & 12.67 & 24.81 \\
PFH & Physical fitness and hygiene & 0.12 & 0.19 & 12.39 & 25.64 \\
GH & Gardening and horticulture & 0.11 & 0.18 & 12.04 & 28.89 \\
POL & Political science & 1.41 & 2.26 & 11.85 & 25.96 \\
SCW & Sciences: comprehensive works & 1.19 & 1.96 & 11.51 & 22.96 \\
CONS & Conservation & 0.16 & 0.28 & 11.24 & 32.73 \\
WS & Women's studies & 0.13 & 0.26 & 9.49 & 17.28 \\
EDU & Education & 1.95 & 3.95 & 9.38 & 18.96 \\
PA & Public administration & 0.16 & 0.34 & 9.22 & 17.89 \\
ANTH & Anthropology & 0.42 & 0.86 & 9.18 & 18.75 \\
SSCW & Social sciences: comprehensive works & 0.61 & 1.38 & 8.36 & 18.48 \\
LAW & Law & 1.09 & 3.24 & 6.41 & 17.12 \\
MIL & Military & 0.10 & 0.29 & 6.18 & 6.90 \\
LING & Linguistics & 0.78 & 2.70 & 5.48 & 12.70 \\
TT & Travel and tourism & 0.09 & 0.33 & 5.03 & 28.13 \\
ARTT & Architecture & 0.09 & 0.36 & 4.59 & 11.59 \\
EI & Ethnic interests & 0.10 & 0.44 & 4.07 & 8.51 \\
PHIL & Philosophy & 0.26 & 1.46 & 3.39 & 6.67 \\
ARCH & Archaeology & 0.17 & 1.33 & 2.48 & 8.11 \\
HIS & History & 0.40 & 4.48 & 1.69 & 4.61 \\
\hline
\end{tabular}

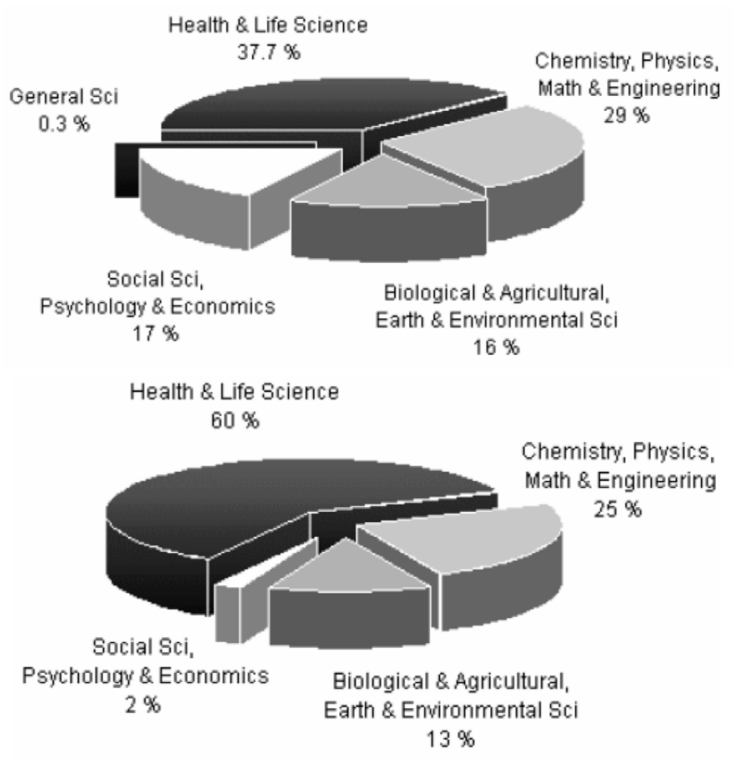

a)

b)

Figure 2. Distribution of journals (a) and records (b) by subject areas in Scopus Source: JACSO, Current Science, 89 (9) (2004) 1537-1547 


\section{Distribution by country of publication}

According to Ulrich's Website data, Scopus has journals from 97 different countries. Figure 3 shows distribution by country of publication and dispersal for the two collections. Those with more than 10 titles are shown, standing as approximately $99 \%$ of the total. A general parallel trend can be drawn regarding distribution $\left(r^{2}=0.95\right)$; and Pearson's correlation coefficient for both collections is 0.98 . Proportionately, then, Scopus's geographical coverage is similar to Ulrich's except in the United Kingdom, Netherlands and Germany.

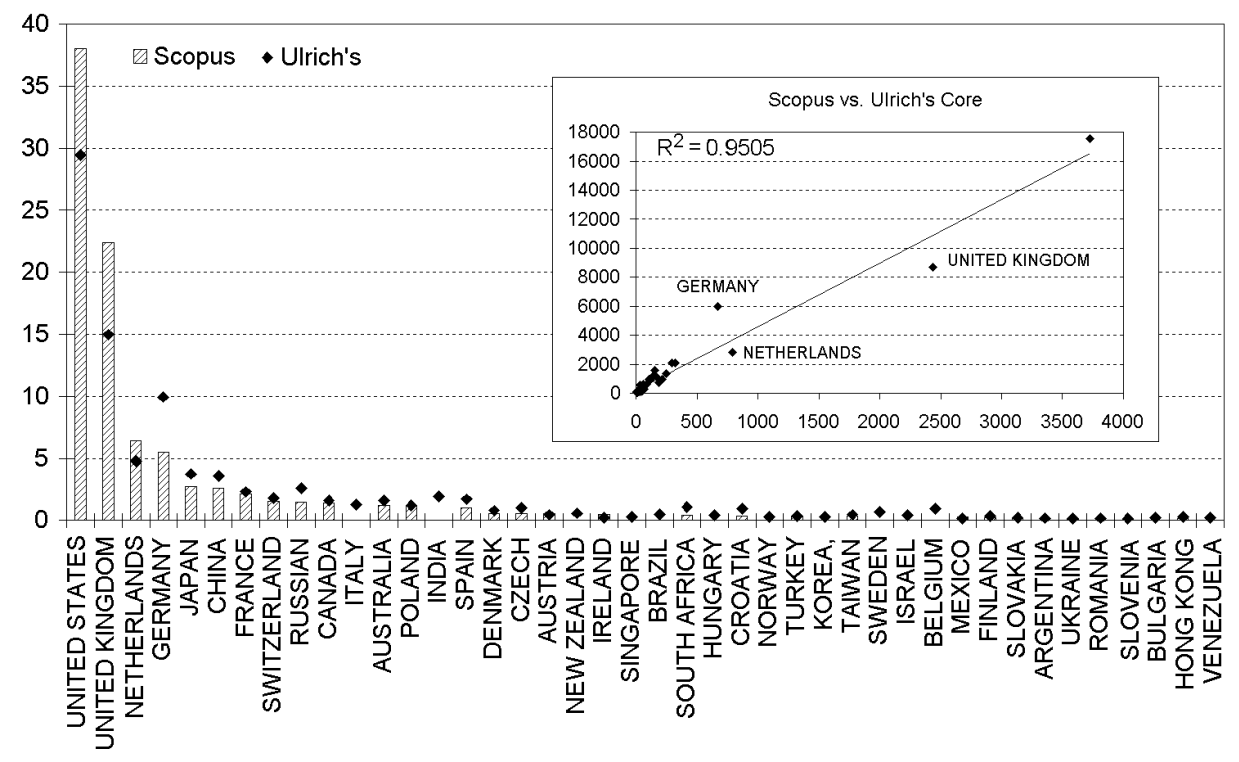

Figure 3. Journal distribution by countries (Ulrich's Core)

Table 4 shows the data for each country with at least ten journals. Taking into account that the percentage of Scopus in relation to Core is $20.40 \%$, then the countries above the average (12\%) and harbouring $70 \%$ of the titles are the U.S, United Kingdom, Netherlands and Russia among others. The Netherlands is over-represented in the sense that its small geographical size houses a major publishing industry. Here, the significant role of Elsevier is evident. The case in United Kingdom stands out with the greatest number of journals. Approximately 33\% of countries are above the number of peerreviewed titles in the collection. 
F. DE MOYA-ANEGÓN et al.: Coverage analysis of Scopus

Table 4. Geographic ranking according to the percentage of Scopus journals in Ulrich's Core

\begin{tabular}{|c|c|c|c|c|}
\hline Country & \%Scopus & $\%$ Ulrich & $\% \mathrm{~S} / \mathrm{U}$ & $\%$ Ref S/U \\
\hline United States & 33.58 & 29.45 & 21.61 & 32.98 \\
\hline United Kingdom & 23.82 & 14.94 & 30.20 & 39.39 \\
\hline Netherlands & 7.53 & 4.73 & 30.15 & 38.23 \\
\hline Germany & 6.58 & 9.91 & 12.58 & 33.84 \\
\hline Japan & 2.80 & 3.57 & 14.86 & 30.21 \\
\hline China & 2.71 & 3.73 & 13.81 & 30.68 \\
\hline France & 2.18 & 2.28 & 18.08 & 40.44 \\
\hline Switzerland & 1.67 & 1.59 & 19.79 & 35.85 \\
\hline Russian Federation & 1.43 & 1.26 & 21.57 & 39.06 \\
\hline Canada & 1.54 & 1.77 & 16.48 & 27.34 \\
\hline Australia & 1.34 & 2.10 & 12.15 & 12.66 \\
\hline Italy & 1.32 & 2.59 & 9.63 & 27.25 \\
\hline India & 1.17 & 1.58 & 14.02 & 22.86 \\
\hline Poland & 1.17 & 1.89 & 11.71 & 23.91 \\
\hline Spain & 0.98 & 1.69 & 10.96 & 24.29 \\
\hline Denmark & 0.78 & 1.09 & 13.62 & 30.40 \\
\hline Czech Republic & 0.56 & 0.44 & 24.07 & 44.53 \\
\hline Austria & 0.54 & 1.01 & 10.10 & 27.51 \\
\hline Singapore & 0.49 & 0.57 & 16.28 & 40.77 \\
\hline Brazil & 0.47 & 0.79 & 11.30 & 16.47 \\
\hline New Zealand & 0.47 & 0.43 & 20.77 & 30.52 \\
\hline Ireland & 0.43 & 0.31 & 26.32 & 53.93 \\
\hline Croatia & 0.41 & 0.23 & 34.31 & 47.14 \\
\hline Hungary & 0.39 & 0.44 & 16.73 & 27.17 \\
\hline Turkey & 0.37 & 0.30 & 23.50 & 29.66 \\
\hline Korea, Republic of & 0.36 & 0.29 & 23.86 & 45.76 \\
\hline South Africa & 0.36 & 0.64 & 10.49 & 18.32 \\
\hline Taiwan & 0.34 & 0.29 & 22.29 & 29.82 \\
\hline Norway & 0.31 & 0.45 & 13.24 & 28.28 \\
\hline Sweden & 0.31 & 0.97 & 6.11 & 17.39 \\
\hline Finland & 0.28 & 0.49 & 10.81 & 28.41 \\
\hline Israel & 0.28 & 0.35 & 14.81 & 29.07 \\
\hline Mexico & 0.27 & 0.42 & 12.16 & 22.55 \\
\hline Belgium & 0.26 & 0.95 & 5.21 & 7.95 \\
\hline Slovakia & 0.23 & 0.17 & 24.53 & 40.00 \\
\hline Hong Kong & 0.14 & 0.14 & 19.28 & 16.67 \\
\hline Venezuela & 0.14 & 0.19 & 13.91 & 17.28 \\
\hline Argentina & 0.13 & 0.31 & 7.98 & 17.86 \\
\hline Ukraine & 0.13 & 0.22 & 11.11 & 15.79 \\
\hline Romania & 0.13 & 0.28 & 8.72 & 14.55 \\
\hline
\end{tabular}

\section{Language of publication}

Roughly $85 \%$ of Scopus journals are written in English, underlining that the coverage of scientific output differs tremendously from general information journals. Similarity between the two collections is 0.96 . Figure 4 shows the percentage distribution, and the tendency line is traced on the subgraph not taking English into 
account. The determination coefficient is 0.9 , or 0.99 when taking the collection of journals in English into account.

Apart from English, Ulrich's coverage shows Slovak, Croatian and Czech to be over-represented and lie above the average for refereed journals (Table 5).

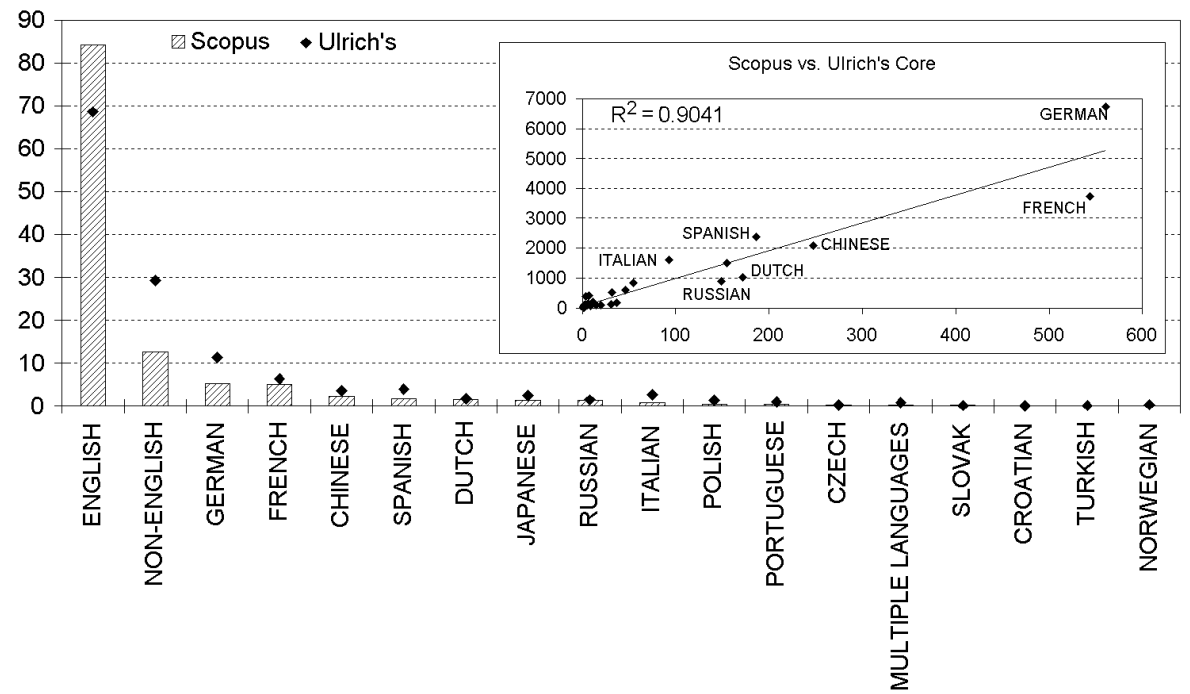

Figure 4. Distribution of journals by language of publication (Ulrich's Core)

Table 5. Linguistic ranking according to the percentage of Scopus journals in Ulrich's Core

\begin{tabular}{lcccc}
\hline Language & \%Scopus & \% Ulrich & \%S/U & \% Ref S/U \\
\hline Croatian & 0.23 & 0.15 & 30.23 & 36.59 \\
Slovak & 0.27 & 0.20 & 27.68 & 45.45 \\
English & 84.74 & 73.77 & 22.36 & 34.58 \\
Czech & 0.32 & 0.31 & 21.14 & 40.00 \\
Turkish & 0.16 & 0.17 & 18.37 & 21.15 \\
Dutch & 1.59 & 1.81 & 17.91 & 26.93 \\
French & 4.96 & 6.75 & 15.00 & 27.81 \\
Russian & 1.04 & 1.58 & 13.47 & 24.31 \\
Korean & 0.10 & 0.16 & 12.35 & 23.53 \\
Chinese & 2.28 & 4.03 & 11.55 & 22.84 \\
Japanese & 1.28 & 2.72 & 9.56 & 19.50 \\
German & 5.34 & 12.02 & 9.07 & 26.16 \\
Portuguese & 1.08 & 8.21 & 11.63 \\
Spanish & 0.43 & 4.48 & 7.91 & 15.33 \\
Non-english & 1.73 & 31.76 & 7.87 & 19.34 \\
Multiple languages & 12.25 & 0.97 & 6.75 & 18.03 \\
Polish & 0.32 & 1.52 & 5.92 & 13.59 \\
Italian & 0.44 & 2.85 & 5.66 & 13.11 \\
Norwegian & 0.79 & 0.37 & 5.29 & 8.16 \\
\hline
\end{tabular}




\section{Distribution by publishers}

In this section standardised information from the Top Publishers is used, supplied by Ulrich's Directory. Figure 5 shows the distribution of the two journal collections by top publishers. Pearson's correlation coefficient is 0.98 and the squared R is 0.96 .

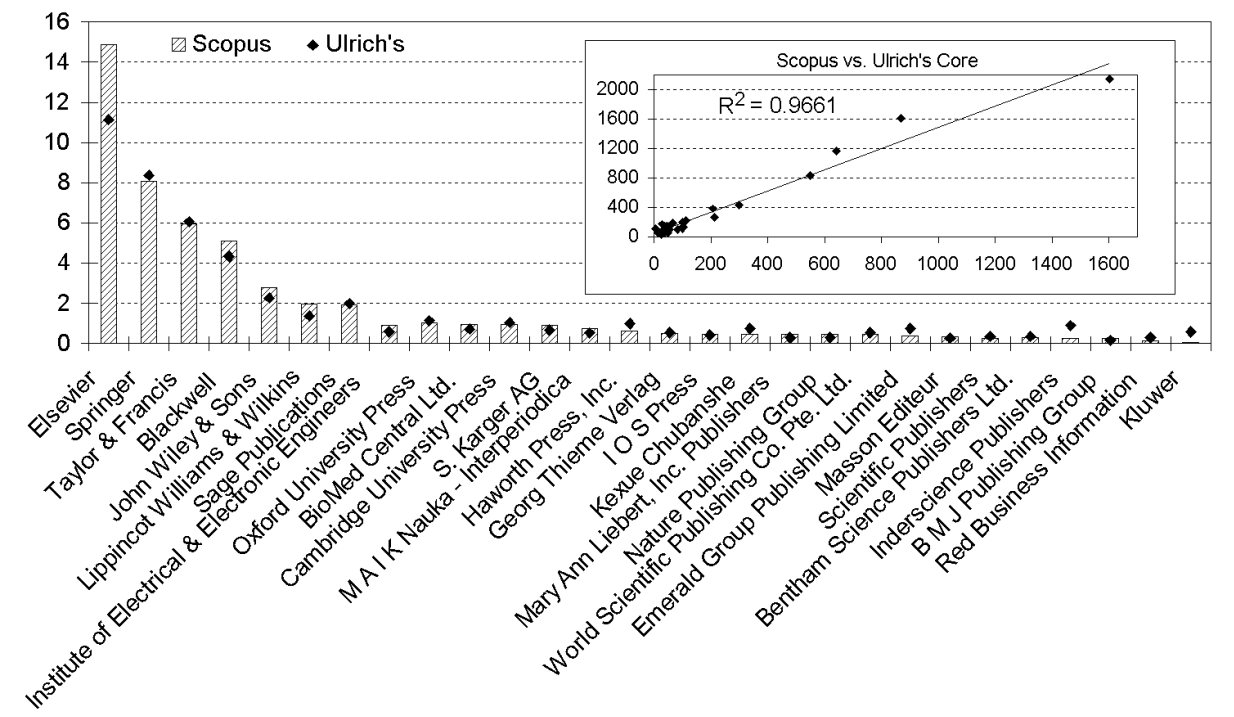

Figure 5. Journal distribution by publishers

Table 6 clearly illustrates how the vast majority of publishers (97\%) are overrepresented in both versions (Ulrich's Core and Scopus). These figures differ from the distributions by subject areas, countries and language of publication in that there is a small group above the average as opposed to a much larger one in the distribution which does not reach it. Interscience is the only exception. As far as refereed journals, $96.3 \%$ of publishers are above the average, again with the exception of Inderscience, while all of them are above the average for journals in the JCR.

\section{Subject distribution in main countries}

The United States. The US collection is $33.58 \%$ and $21.61 \%$ in Ulrich's Core. Subject coverage is $78.38 \%$ in relation to Ulrich's Core, of which $47.41 \%$ of the categories are Sciences and comprise nearly $70 \%$ of journals. 
F. DE MOYA-ANEGÓN et al.: Coverage analysis of Scopus

Table 6. Ranking by 'Scopus' publishers according to the coverage percentage in Ulrich's Core

\begin{tabular}{|c|c|c|c|c|c|}
\hline Publishers & \%Scopus & $\%$ Ulrich & $\% \mathrm{~S} / \mathrm{U}$ & $\% \operatorname{Ref} \mathrm{S} / \mathrm{U}$ & $\% \mathrm{ISI} / \mathrm{UC}$ \\
\hline $\begin{array}{l}\text { Institute of Electrical \& Electronic } \\
\text { Engineers }\end{array}$ & 0.92 & 0.58 & 88.39 & 97.80 & 94.44 \\
\hline B M J Publishing Group & 0.25 & 0.17 & 84.38 & 91.67 & 94.44 \\
\hline Mary Ann Liebert, Inc. Publishers & 0.45 & 0.30 & 84.21 & 85.45 & 96.88 \\
\hline Nature Publishing Group & 0.45 & 0.30 & 82.76 & 86.00 & 100.00 \\
\hline M A I K Nauka - Interperiodica & 0.76 & 0.52 & 82.00 & 86.59 & 97.22 \\
\hline Lippincot Williams \& Wilkins & 1.97 & 1.38 & 80.30 & 91.44 & 98.61 \\
\hline S. Karger AG & 0.91 & 0.66 & 77.78 & 78.57 & 100.00 \\
\hline Elsevier & 14.87 & 11.15 & 74.86 & 81.65 & 97.37 \\
\hline BioMed Central Ltd. & 0.97 & 0.72 & 74.82 & 76.56 & 83.33 \\
\hline John Wiley \& Sons & 2.77 & 2.27 & 68.58 & 79.38 & 94.66 \\
\hline Masson Editeur & 0.33 & 0.28 & 67.92 & 100.00 & 100.00 \\
\hline Blackwel & 5.09 & 4.32 & 66.14 & 72.87 & 97.70 \\
\hline I O S Press & 0.45 & 0.42 & 60.49 & 68.12 & 100.00 \\
\hline Taylor \& Francis & 5.96 & 6.06 & 55.15 & 62.18 & 95.94 \\
\hline Springer & 8.07 & 8.37 & 54.14 & 63.41 & 97.58 \\
\hline Sage Publications & 1.92 & 2.00 & 53.91 & 58.79 & 96.45 \\
\hline Georg Thieme Verlag & 0.51 & 0.54 & 52.88 & 62.67 & 86.11 \\
\hline Oxford University Press & 1.04 & 1.14 & 51.14 & 58.92 & 97.96 \\
\hline Cambridge University Press & 0.94 & 1.05 & 50.00 & 66.18 & 100.00 \\
\hline World Scientific Publishing Co. Pte. Ltd. & 0.45 & 0.54 & 47.12 & 58.75 & 100.00 \\
\hline Bentham Science Publishers Ltd. & 0.29 & 0.35 & 46.27 & 55.56 & 100.00 \\
\hline Scientific Publishers & 0.25 & 0.35 & 39.71 & 53.66 & 100.00 \\
\hline Haworth Press, Inc. & 0.61 & 1.01 & 34.20 & 38.56 & 93.75 \\
\hline Kexue Chubanshe & 0.45 & 0.76 & 33.10 & 38.14 & 85.71 \\
\hline Emerald Group Publishing Limited & 0.39 & 0.73 & 29.79 & 33.04 & 96.00 \\
\hline Red Business Information & 0.14 & 0.30 & 26.32 & 60.00 & 75.00 \\
\hline Interscience Publishers & 0.27 & 0.90 & 16.86 & 17.18 & 80.00 \\
\hline
\end{tabular}

Meanwhile, $35.34 \%$ of categories are from the Social Sciences with $25.46 \%$ of journals and the rest are from Humanities. Similarity between the two collections is 0.9 and the straight line adjustment is 0.82 for all categories; and 0.97 when those which are accompanied by an abbreviation in the subgraph are excluded (mainly from the Social Sciences and Humanities).

Table 7 shows categories with more than ten titles in descending order of the percentage of journals found in Ulrich's Core. Nearly $73 \%$ of the categories are overrepresented, and are above the average for peer-reviewed journals. These categories mainly belong to areas related to Sciences and Engineering (69\%).

United Kingdom. The collection of journals from the UK found makes up 30\% of Ulrich's Core, while accounting for $23.82 \%$ of the total in Scopus. The subject coverage is $66 \%$. There is over-representation of $82 \%$ of the categories shown in Table $8,74 \%$ of which are from the Sciences. Also, $71 \%$ are above the average for Scopus in peerreviewed journals, with $82 \%$ of categories from Sciences and Engineering. The correlation coefficient for whole distribution is 0.95 . 
F. DE MOYA-ANEGÓN et al.: Coverage analysis of Scopus

Table 7. Subject ranking according to the coverage percentage in Ulrich's Core - United States

\begin{tabular}{|c|c|c|c|c|c|}
\hline Abr. & Ulrich's subject & \%Scopus & $\%$ Ulrich & $\% \mathrm{~S} / \mathrm{U}$ & $\% \operatorname{Ref} \mathrm{S} / \mathrm{U}$ \\
\hline VET & Veterinary Science & 0.77 & 0.30 & 56.60 & 63.83 \\
\hline ENG & Engineering & 5.71 & 2.56 & 48.15 & 55.66 \\
\hline GEO & Geography & 0.65 & 0.31 & 44.64 & 52.50 \\
\hline ENE & Energy & 0.65 & 0.32 & 43.86 & 57.14 \\
\hline ELE & Electronics & 0.65 & 0.33 & 41.67 & 42.55 \\
\hline MET & Metallurgy & 0.31 & 0.17 & 38.71 & 46.15 \\
\hline DAA & Drug Abuse and Alcoholism & 0.49 & 0.28 & 38.00 & 52.78 \\
\hline MED & Medical Sciences & 26.65 & 15.20 & 37.89 & 44.88 \\
\hline PHY & Physics & 2.48 & 1.42 & 37.65 & 40.65 \\
\hline PSY & Psychology & 5.66 & 3.30 & 37.06 & 47.59 \\
\hline $\mathrm{CHE}$ & Chemistry & 2.76 & 1.61 & 37.02 & 42.92 \\
\hline GERON & Gerontology and Geriatrics & 0.88 & 0.52 & 36.56 & 49.25 \\
\hline PHAR & Pharmacy and Pharmacology & 1.86 & 1.10 & 36.36 & 40.26 \\
\hline FF & Fish and Fisheries & 0.26 & 0.16 & 35.71 & 43.48 \\
\hline PETR & Petroleum and Gas & 0.28 & 0.17 & 35.48 & 50.00 \\
\hline $\mathrm{BIOL}$ & Biology & 9.01 & 5.55 & 35.08 & 42.14 \\
\hline FOOD & Food and Food Industries & 0.46 & 0.30 & 33.96 & 48.48 \\
\hline NUT & Nutrition and Dietetics & 0.54 & 0.35 & 33.87 & 44.68 \\
\hline HAN & Handicapped & 0.31 & 0.21 & 32.43 & 40.91 \\
\hline MATH & Mathematics & 3.05 & 2.07 & 31.81 & 38.51 \\
\hline COMP & Computers & 4.36 & 3.02 & 31.24 & 39.49 \\
\hline ENV & Environmental Studies & 1.89 & 1.31 & 31.20 & 45.58 \\
\hline $\mathrm{HOU}$ & Housing and Urban Planning & 0.36 & 0.25 & 31.11 & 43.33 \\
\hline ES & Earth Sciences & 1.55 & 1.13 & 29.70 & 39.10 \\
\hline SSWE & Social Services and Welfare & 0.96 & 0.75 & 27.61 & 34.88 \\
\hline PHS & Public Health and Safety & 0.54 & 0.43 & 27.27 & 38.00 \\
\hline AGRI & Agriculture & 1.08 & 0.88 & 26.75 & 41.30 \\
\hline AERO & Aeronautics and Space Flight & 0.39 & 0.33 & 25.00 & 30.00 \\
\hline SOC & Sociology & 1.52 & 1.43 & 23.05 & 35.85 \\
\hline CRIM & Criminology and Law Enforcement & 0.52 & 0.50 & 22.22 & 37.78 \\
\hline HFA & Health Facilities and Administration & 0.31 & 0.31 & 21.82 & 37.93 \\
\hline $\mathrm{BE}$ & Business and Economics & 5.06 & 5.17 & 21.17 & 29.19 \\
\hline SSCW & Social Sciences: Comprehensive Works & 0.75 & 0.81 & 20.00 & 29.67 \\
\hline CYABOUT & Children and Youth_About & 0.31 & 0.37 & 17.91 & 33.33 \\
\hline SCW & Sciences: Comprehensive Works & 0.85 & 1.07 & 17.19 & 23.81 \\
\hline COMM & Communications & 0.57 & 0.73 & 16.92 & 29.03 \\
\hline POL & Political Science & 1.60 & 2.08 & 16.67 & 30.32 \\
\hline ANTH & Anthropology & 0.72 & 0.94 & 16.57 & 27.45 \\
\hline TRAN & Transportation & 0.36 & 0.47 & 16.47 & 42.31 \\
\hline LIS & Library and Information Sciences & 0.65 & 1.05 & 13.23 & 18.35 \\
\hline EDU & Education & 2.89 & 4.79 & 13.05 & 20.77 \\
\hline LAW & Law & 2.40 & 4.46 & 11.64 & 30.56 \\
\hline LING & Linguistics & 0.52 & 1.25 & 8.93 & 14.60 \\
\hline HIS & History & 0.34 & 3.32 & 2.18 & 4.44 \\
\hline
\end{tabular}




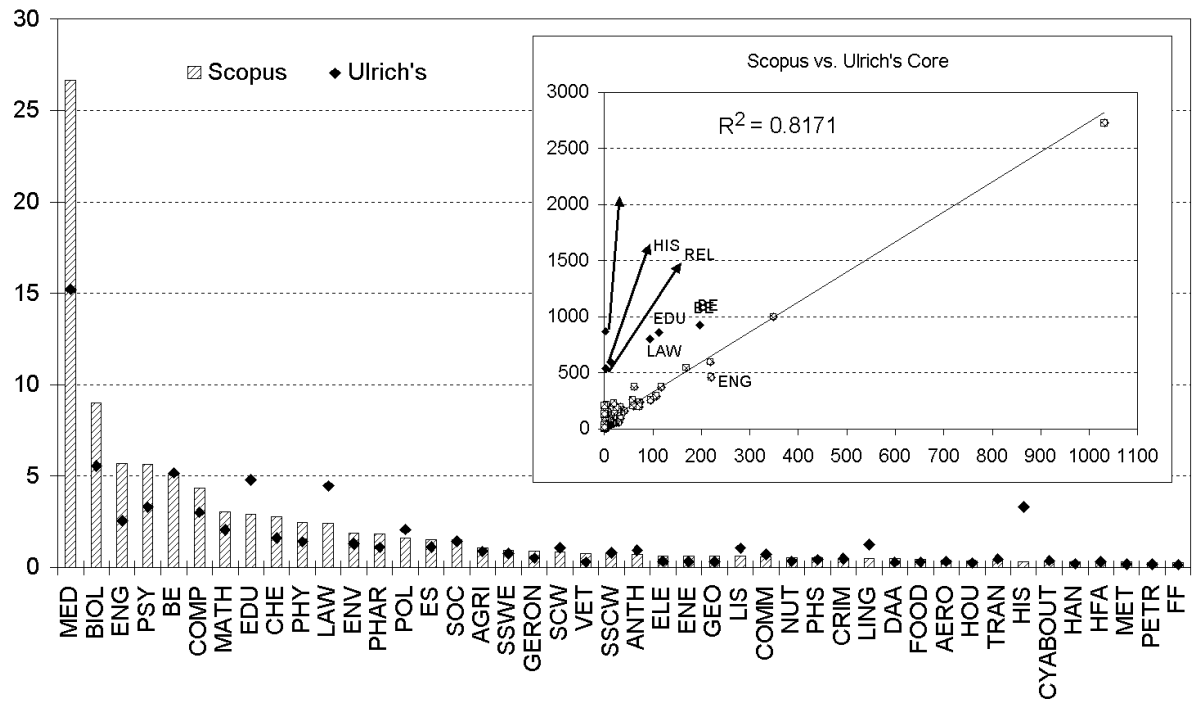

Figure 6. Percentage distribution of journals by scientific areas - United States

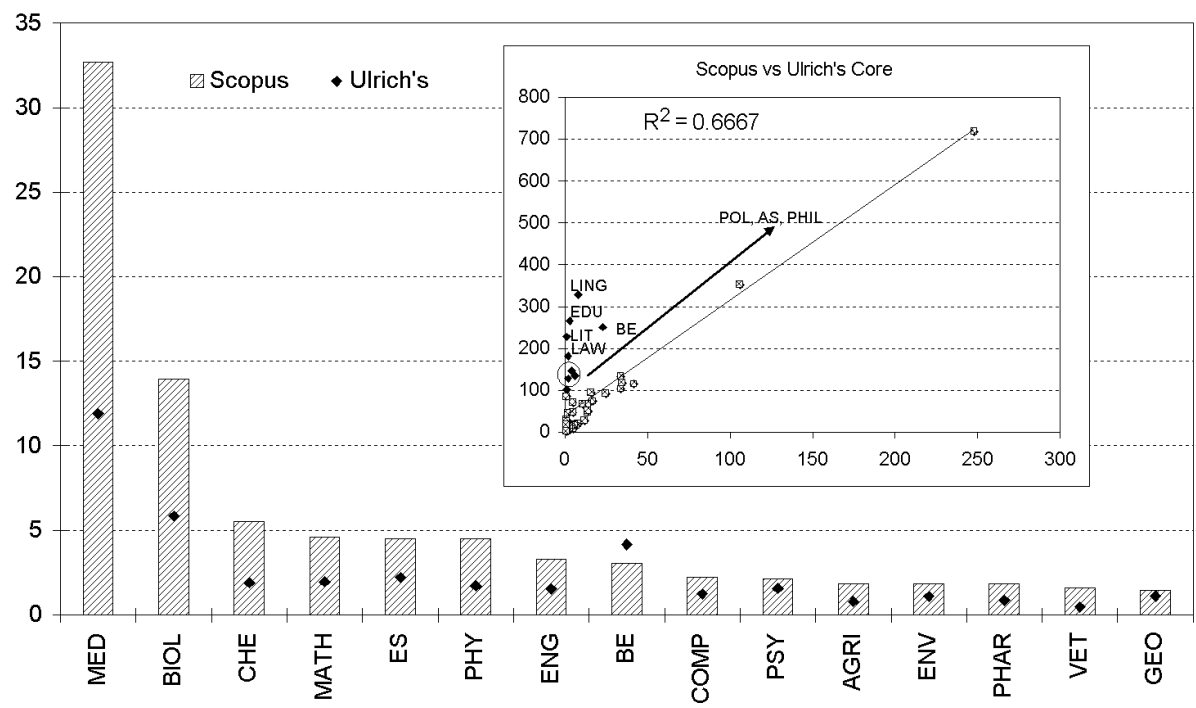

Figure 7. Percentage distribution of journals by scientific areas -United Kingdom 
F. DE MOYA-ANEGÓN et al.: Coverage analysis of Scopus

Table 8. Subject ranking according to the percentage of Scopus journals in Ulrich's Core - United Kingdom

\begin{tabular}{|c|c|c|c|c|c|}
\hline Abr. & Ulrich's subject & \%Scopus & $\%$ Ulrich & $\% \mathrm{~S} / \mathrm{U}$ & $\% \operatorname{Ref} \mathrm{S} / \mathrm{U}$ \\
\hline ELE & Electronics & 0.47 & 0.23 & 61.90 & 61.11 \\
\hline PHAR & Pharmacy and Pharmacology & 2.11 & 1.11 & 57.43 & 62.82 \\
\hline PHS & Public Health and Safety & 1.06 & 0.56 & 56.86 & 64.29 \\
\hline MET & Metallurgy & 0.69 & 0.38 & 54.29 & 65.22 \\
\hline PHY & Physics & 2.84 & 1.67 & 51.32 & 56.25 \\
\hline ENE & Energy & 1.09 & 0.65 & 50.85 & 56.52 \\
\hline ENG & Engineering & 5.90 & 3.64 & 48.94 & 56.65 \\
\hline ES & Earth Sciences & 2.22 & 1.37 & 48.80 & 54.63 \\
\hline PLAS & Plastics & 0.55 & 0.34 & 48.39 & 56.52 \\
\hline WR & Water Resources & 0.36 & 0.23 & 47.62 & 58.82 \\
\hline BIOL & Biology & 10.01 & 6.73 & 44.93 & 51.93 \\
\hline VET & Veterinary Science & 0.47 & 0.32 & 44.83 & 48.15 \\
\hline NUT & Nutrition and Dietetics & 0.62 & 0.42 & 44.74 & 51.72 \\
\hline $\mathrm{CHE}$ & Chemistry & 3.10 & 2.14 & 43.59 & 52.45 \\
\hline GEO & Geography & 1.02 & 0.71 & 43.08 & 53.06 \\
\hline MED & Medical Sciences & 21.34 & 15.00 & 42.96 & 51.02 \\
\hline PSY & Psychology & 3.50 & 2.52 & 41.92 & 47.89 \\
\hline STA & Statistics & 0.40 & 0.30 & 40.74 & 45.83 \\
\hline $\mathrm{HOU}$ & Housing and Urban Planning & 0.80 & 0.60 & 40.00 & 50.00 \\
\hline ENV & Environmental Studies & 2.15 & 1.66 & 39.07 & 47.75 \\
\hline AGRI & Agriculture & 1.42 & 1.14 & 37.50 & 48.57 \\
\hline COMP & Computers & 3.31 & 2.72 & 36.84 & 38.46 \\
\hline TRAN & Transportation & 1.09 & 0.92 & 35.71 & 38.10 \\
\hline MATH & Mathematics & 1.97 & 1.69 & 35.06 & 42.37 \\
\hline LIS & Library and Information Sciences & 1.20 & 1.06 & 34.38 & 50.00 \\
\hline SOC & Sociology & 1.46 & 1.50 & 29.41 & 35.45 \\
\hline $\mathrm{BE}$ & Business and Economics & 7.83 & 8.83 & 26.77 & 32.08 \\
\hline SCW & Sciences: Comprehensive Works & 0.76 & 0.92 & 25.00 & 31.03 \\
\hline LING & Linguistics & 1.38 & 1.69 & 24.68 & 34.44 \\
\hline POL & Political Science & 2.95 & 3.88 & 22.95 & 32.05 \\
\hline SSCW & Social Sciences: Comprehensive Works & 0.91 & 1.34 & 20.49 & 28.75 \\
\hline SSWE & Social Services and Welfare & 0.58 & 0.93 & 18.82 & 31.11 \\
\hline COMM & Communications & 0.44 & 0.71 & 18.46 & 26.83 \\
\hline EDU & Education & 2.55 & 4.75 & 16.20 & 24.40 \\
\hline PHIL & Philosophy & 0.51 & 1.29 & 11.97 & 13.79 \\
\hline HIS & History & 0.98 & 3.30 & 9.00 & 12.79 \\
\hline $\mathrm{ARCH}$ & Archaeology & 0.36 & 1.41 & 7.81 & 12.90 \\
\hline LAW & Law & 0.58 & 2.30 & 7.66 & 15.73 \\
\hline
\end{tabular}

The Netherlands. It represents $30.15 \%$ of the total of Scopus in Ulrich's Core and $7.53 \%$ of the Scopus collection. Its subject coverage is $62.4 \%$. With the exception of Linguistics and Law, all the categories shown in Table 9 are over-represented, and far above the average for peer-reviewed journals, mainly from the Sciences $(86 \%)$. The Pearson coefficient is 0.92 . Table 9 shows those which have 10 or more journals. 


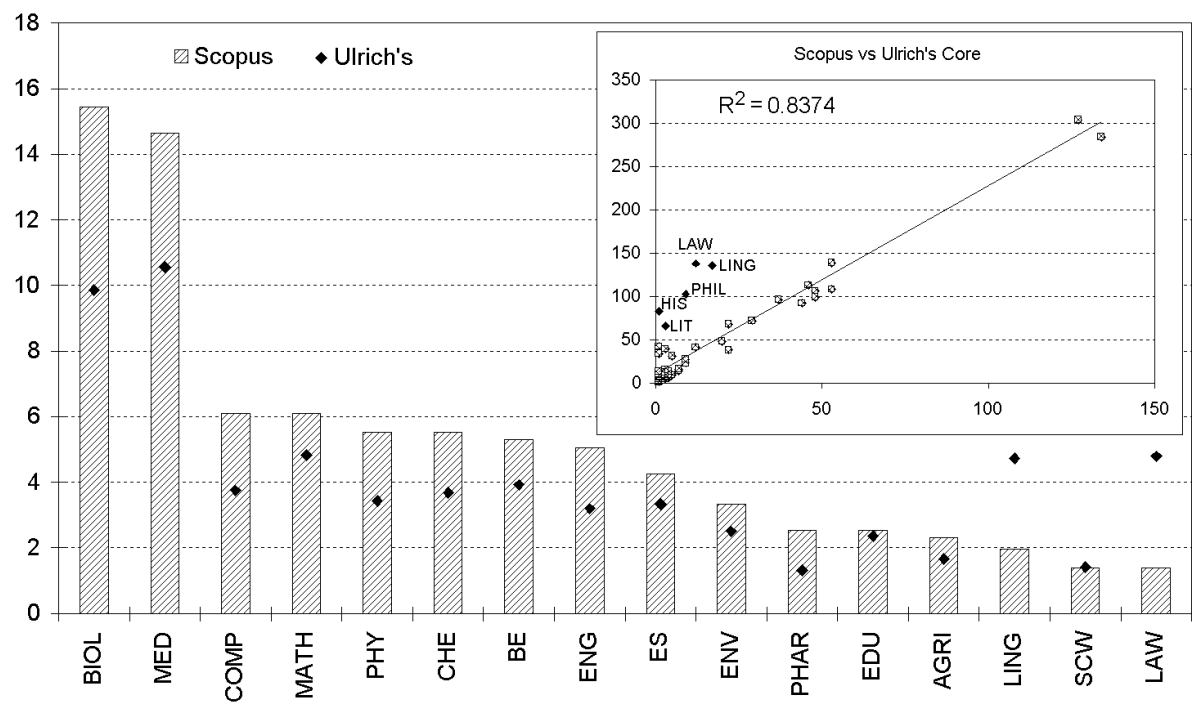

Figure 8. Percentage distribution of journals by subject areas in Ulrich's Core-The Netherlands

Table 9. Subject ranking according to the percentage of Scopus journals in Ulrich's Core -The Netherlands

\begin{tabular}{llrrrc}
\hline \multicolumn{1}{c}{ Abr. } & \multicolumn{1}{c}{ Ulrich's subject } & \%Scopus & \% Ulrich & \% $/ \mathrm{U}$ & \% Ref S/U \\
\hline PHAR & Pharmacy and Pharmacology & 2.53 & 1.32 & 57.89 & 65.63 \\
COMP & Computers & 6.11 & 3.75 & 49.07 & 55.56 \\
PHY & Physics & 5.53 & 3.44 & 48.48 & 51.69 \\
ENG & Engineering & 5.07 & 3.20 & 47.83 & 51.28 \\
BIOL & Biology & 15.44 & 9.86 & 47.18 & 51.65 \\
CHE & Chemistry & 5.53 & 3.68 & 45.28 & 50.57 \\
MED & Medical Sciences & 14.63 & 10.56 & 41.78 & 44.35 \\
AGRI & Agriculture & 2.30 & 1.67 & 41.67 & 55.56 \\
BE & Business and Economics & 5.30 & 3.92 & 40.71 & 53.57 \\
ENV & Environmental Studies & 3.34 & 2.50 & 40.28 & 51.02 \\
ES & Earth Sciences & 4.26 & 3.33 & 38.54 & 41.77 \\
MATH & Mathematics & 6.11 & 4.83 & 38.13 & 43.12 \\
EDU & Education & 2.53 & 2.36 & 32.35 & 42.22 \\
SCW & Sciences: Comprehensive Works & 1.38 & 1.42 & 29.27 & 37.93 \\
LING & Linguistics & 1.96 & 4.72 & 12.50 & 16.67 \\
LAW & Law & 1.38 & 4.79 & 8.70 & 15.79 \\
\hline
\end{tabular}

Germany. It represents $12.57 \%$ in Ulrich's Core and $6.58 \%$ of the Scopus total. It has output in $45.6 \%$ of the Ulrich categories in which Germany publishes. Out of the categories shown in Table $10,80 \%$ are above the average in relation to the Ulrich collection, all from the Sciences, Medicine and Engineering. In relation to the country, $87 \%$ of peer-reviewed journals are above the average and all are from Sciences except Geography. The similarity value between the two collections is 0.82 . 


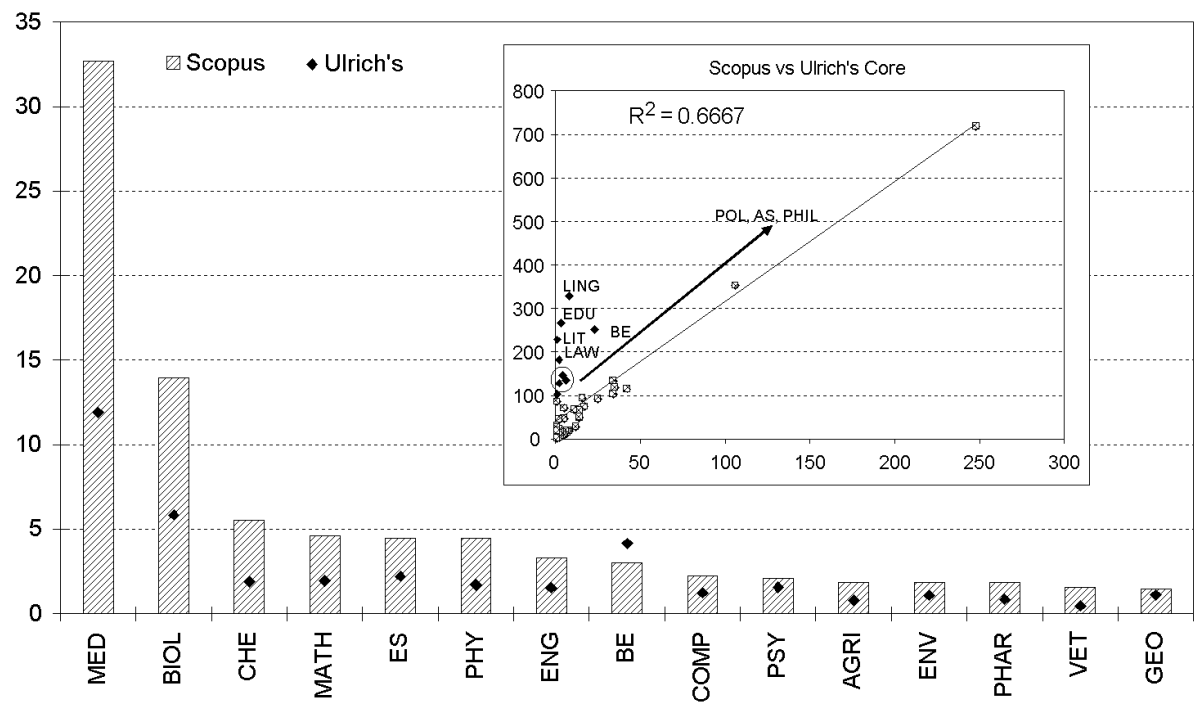

Figure 9. Percentage distribution of journals by subject areas in Ulrich's Core - Germany

Table 10. Subject ranking according to the percentage of Scopus journals in Ulrich's Core - Germany

\begin{tabular}{llrrrr}
\hline \multicolumn{1}{c}{ Abr. } & \multicolumn{1}{c}{ Ulrich's Subject } & \%Scopus & \% Ulrich & \%S/U & \% Ref S/U \\
\hline VET & Veterinary Science & 1.58 & 0.46 & 42.86 & 66.67 \\
CHE & Chemistry & 5.53 & 1.91 & 36.52 & 41.49 \\
MED & Medical Sciences & 32.67 & 11.90 & 34.54 & 46.53 \\
PHY & Physics & 4.48 & 1.71 & 33.01 & 45.71 \\
BIOL & Biology & 13.97 & 5.83 & 30.11 & 48.31 \\
MATH & Mathematics & 4.61 & 1.95 & 29.66 & 42.50 \\
AGRI & Agriculture & 1.84 & 0.80 & 29.17 & 55.00 \\
PHAR & Pharmacy and Pharmacology & 1.84 & 0.84 & 27.45 & 52.00 \\
ENG & Engineering & 3.29 & 1.52 & 27.17 & 37.74 \\
ES & Earth Sciences & 4.48 & 2.20 & 25.56 & 41.38 \\
COMP & Computers & 2.24 & 1.23 & 22.97 & 36.36 \\
ENV & Environmental Studies & 1.84 & 1.09 & 21.21 & 50.00 \\
PSY & Psychology & 2.11 & 1.56 & 17.02 & 30.30 \\
GEO & Geography & 1.45 & 1.11 & 16.42 & 38.46 \\
BE & Business And Economics & 3.03 & 4.16 & 9.16 & 31.67 \\
\hline
\end{tabular}

\section{Subject distribution according to main publishers}

Elsevier. It represents approximately $15 \%$ of the Scopus collection and $75 \%$ in relation to the whole Elsevier collection in Ulrich's Core. It has journals in $97 \%$ of Ulrich categories, $62 \%$ of which are from the Basic, Experimental and Medical Sciences (accounting for $84.77 \%$ of the number of journals), $13.86 \%$ from Social 
Sciences (with $32.47 \%$ of journals) and $7.8 \%$ from Humanities (scarcely $1.31 \%$ of the titles). In all cases, the values studied are above the average (Table 11). The correlation coefficient is 0.95 and the determination coefficient is 0.99 .

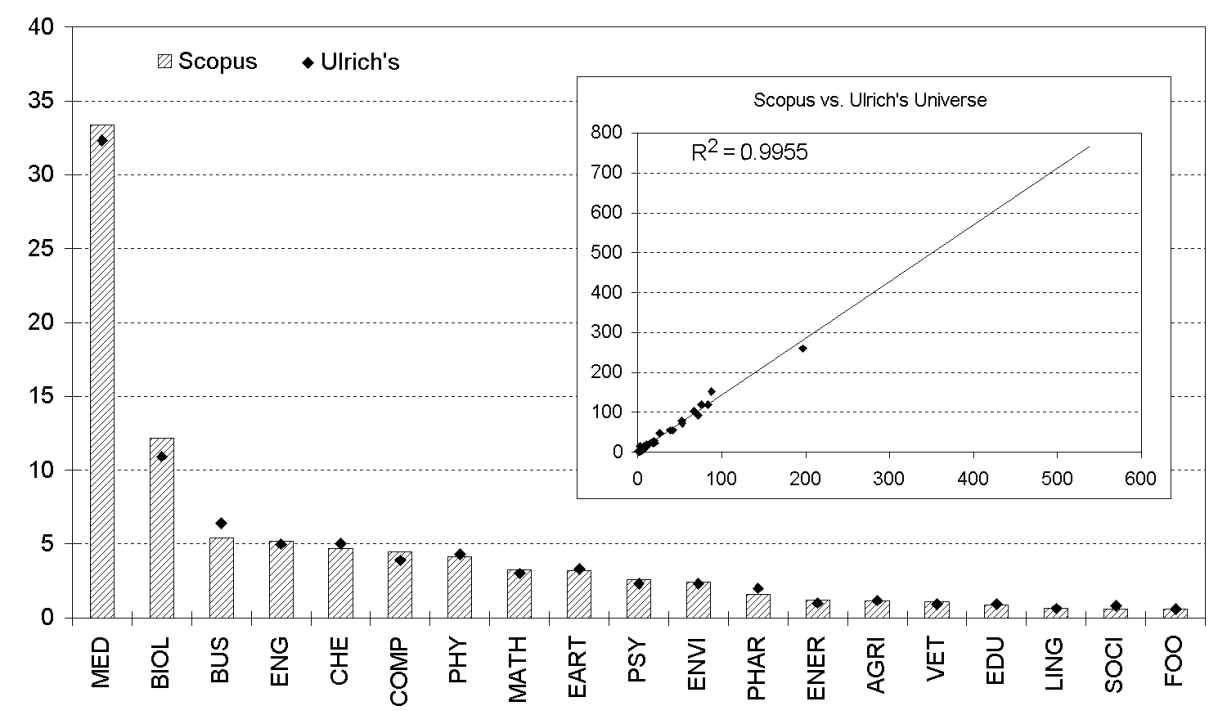

Figure 10. Percentage distribution by subject areas in Ulrich's Core - Elsevier

Table 11. Subject ranking according to the percentage of Scopus journals in Ulrich's Core - Elsevier

\begin{tabular}{llcccc}
\hline Abr. Subject & \multicolumn{1}{c}{ Subject } & \%Scopus & \% Ulrich & \%S/U & \% Ref S/U \\
\hline ENER & Energy & 0.89 & 0.98 & 90.48 & 89.47 \\
BIOL & Biology & 9.26 & 11.03 & 83.90 & 87.91 \\
PSY & Psychology & 1.87 & 2.29 & 81.63 & 86.67 \\
VET & Veterinary Science & 0.79 & 0.98 & 80.95 & 85.00 \\
COMP & Computers & 3.23 & 4.02 & 80.23 & 82.93 \\
ENVI & Environmental Studies & 1.82 & 2.29 & 79.59 & 80.43 \\
MED & Medical Sciences & 24.50 & 31.56 & 77.63 & 83.86 \\
FOO & Food and Food Industries & 0.47 & 0.61 & 76.92 & 90.91 \\
ENG & Engineering & 3.79 & 4.96 & 76.42 & 79.00 \\
MAT & Mathematics & 2.48 & 3.32 & 74.65 & 73.91 \\
LING & Linguistics & 0.51 & 0.70 & 73.33 & 78.57 \\
AGRI & Agriculture & 0.89 & 1.22 & 73.08 & 76.00 \\
PHAR & Pharmacy and Pharmacology & 1.22 & 1.68 & 72.22 & 73.53 \\
EART & Earth Sciences & 2.43 & 3.41 & 71.23 & 73.53 \\
PHY & Physics & 3.09 & 4.44 & 69.47 & 70.97 \\
CHE & Chemistry & 3.55 & 5.38 & 66.09 & 71.13 \\
EDU & Education & 0.65 & 1.03 & 63.64 & 92.86 \\
BUS & Business and Economics & 4.02 & 6.87 & 58.50 & 83.16 \\
\hline
\end{tabular}


Springer. Its publications comprise $8 \%$ of Scopus, in sharp contrast with its presence of $54.14 \%$ in Ulrich's Core. Coverage amounts to $74.42 \%$. The distribution amongst Science categories is $62.5 \%$ with $84.25 \%$ of the collection's journals, $29.69 \%$ for Social Sciences with $13.68 \%$ of the titles and $7.81 \%$ of categories for Humanities with $1.95 \%$ of the journals. With regards to categories having over ten titles, it surpasses all the parameters (Table 12). The similarity value with Ulrich's Core is 0.99 .

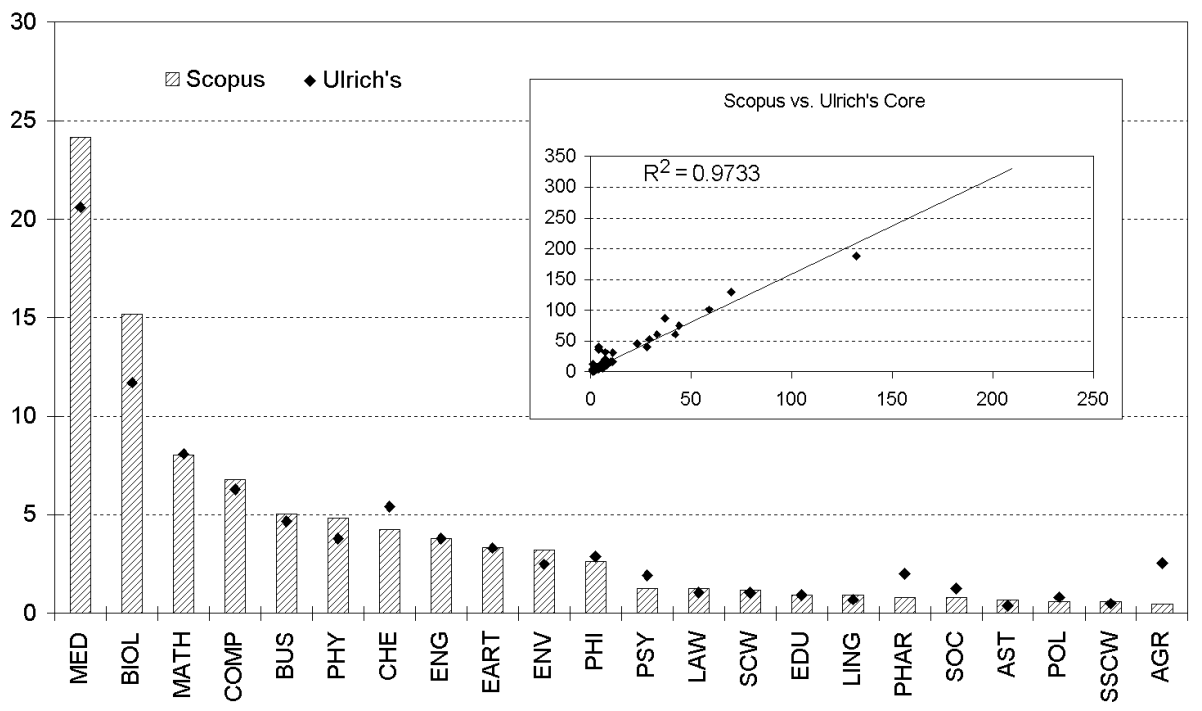

Figure 11. Percentage distribution by subject areas in Ulrich's Core - Springer

Table 12. Subject ranking according to the percentage of Scopus journals in Ulrich's Core - Springer

\begin{tabular}{llrrrr}
\hline \multicolumn{1}{c}{ Abr } & \multicolumn{1}{c}{ Subject } & \%Scopus & \% Ulrich & \%S/U & \% Ref S/U \\
\hline BIOL & Biology & 15.17 & 11.70 & 70.21 & 77.30 \\
PSY & Psychology & 3.22 & 2.49 & 70.00 & 71.79 \\
ENG & Engineering & 4.83 & 3.80 & 68.85 & 78.85 \\
PHAR & Pharmacy and Pharmacology & 1.26 & 1.06 & 64.71 & 78.57 \\
MED & Medical Sciences & 24.14 & 20.60 & 63.44 & 73.38 \\
SOC & Sociology & 1.15 & 1.06 & 58.82 & 71.43 \\
PHY & Physics & 5.06 & 4.67 & 58.67 & 70.49 \\
COM & Computers & 6.78 & 6.29 & 58.42 & 66.25 \\
EAR & Earth Sciences & 3.33 & 3.30 & 54.72 & 62.22 \\
CHE & Chemistry & 3.79 & 3.80 & 54.10 & 60.78 \\
MATH & Mathematics & 8.05 & 8.09 & 53.85 & 64.22 \\
ES & Environmental Studies & 2.64 & 2.86 & 50.00 & 67.74 \\
BE & Business and Economics & 4.25 & 5.41 & 42.53 & 50.72 \\
EDU & Education & 1.26 & 1.93 & 35.48 & 40.00 \\
\hline
\end{tabular}


Taylor \& Francis. Precisely $5.96 \%$ of Scopus journals pertain to this publisher, whereas they make up $55.15 \%$ the Ulrich collection. It covers just over $73 \%$ of the Ulrich Core categories, $55.38 \%$ of which are from scientific areas (accounting for 64.33 journals), $40 \%$ from areas associated with Social Sciences (with 32.87\%) and $4.62 \%$ from Humanities (2.65\% of the total Scopus collection). Table 13 shows categories holding more than 10 titles; with the exception of History and Education in the variable for peer-reviewed journals, all are over-represented. The similarity coefficient is 0.91 . Figure 12 shows the distribution for both collections.

Table 13. Subject ranking according to the percentage of Scopus journals in Ulrich's Core - Taylor \& Francis

\begin{tabular}{llrrrr}
\multicolumn{1}{c}{ Abr. } & \multicolumn{1}{c}{ Subject } & \%Scopus & \% Ulrich & \%S/U & \% Ref S/U \\
\hline HOU & Housing and Urban Planning & 1.71 & 1.12 & 84.62 & 90.91 \\
MED & Medical Sciences & 21.81 & 14.26 & 84.34 & 86.36 \\
PHAR & Pharmacy and Pharmacology & 2.18 & 1.46 & 82.35 & 87.50 \\
ES & Environmental Studies & 4.05 & 2.75 & 81.25 & 84.62 \\
BIOL & Biology & 6.70 & 4.73 & 78.18 & 90.91 \\
PHY & Physics & 3.43 & 2.49 & 75.86 & 78.57 \\
CHE & Chemistry & 5.92 & 4.38 & 74.51 & 80.85 \\
PSY & Psychology & 6.85 & 5.24 & 72.13 & 77.36 \\
MATH & Mathematics & 2.02 & 1.63 & 68.42 & 64.71 \\
ENG & Engineering & 4.67 & 3.87 & 66.67 & 72.97 \\
COM & Computers & 1.87 & 1.72 & 60.00 & 63.16 \\
BE & Business and Economics & 6.54 & 6.10 & 59.15 & 72.73 \\
POL & Political Science & 5.45 & 7.65 & 39.33 & 49.23 \\
EDU & Education & 3.89 & 8.51 & 25.25 & 29.87 \\
HIS & History & 1.56 & 3.87 & 22.22 & 27.03 \\
\hline
\end{tabular}

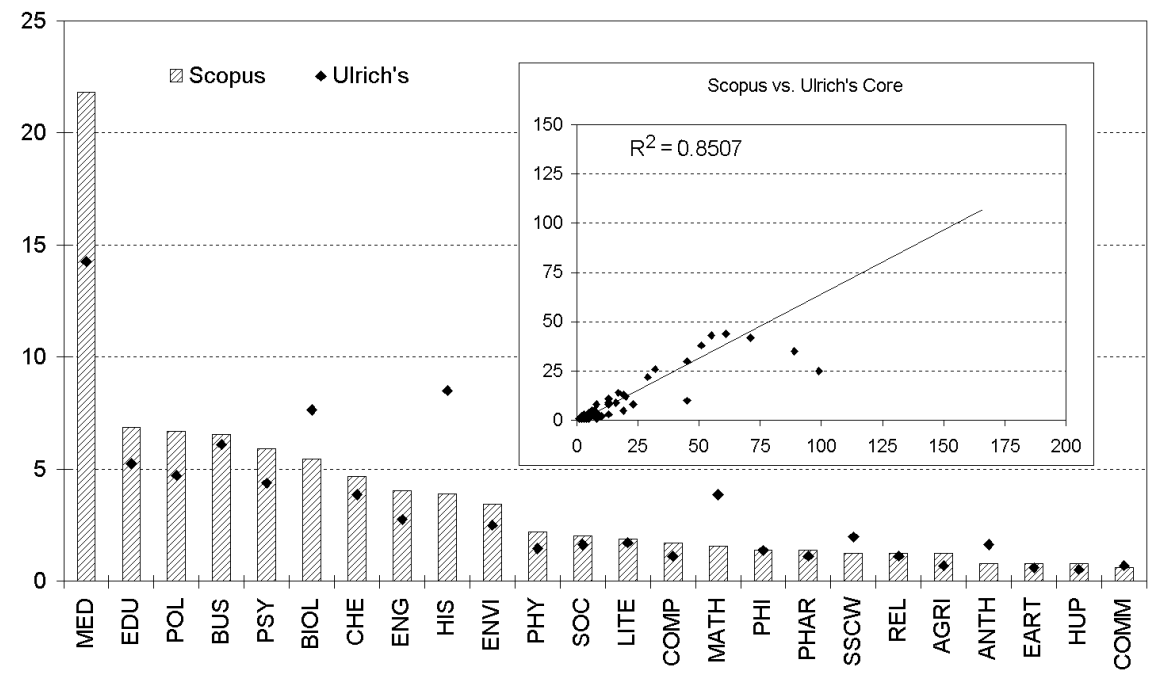

Figure 12. Percentage distribution by subject areas in Ulrich's Core - Taylor \& Francis 
Blackwell. It represents 5\% of Scopus, and $66.14 \%$ of the publisher total in Ulrich's Core. Its subject coverage is $83.33 \%$, with $52 \%$ of the categories associated with Sciences (accounting for $67.4 \%$ of the total journals), $46 \%$ from Social Sciences (with $29.5 \%$ ), and $12 \%$ from Humanities (with a share just under $3 \%$ of journals). The similarity value with Ulrich's Core is 0.99 . It surpasses the average in all aspects studied.

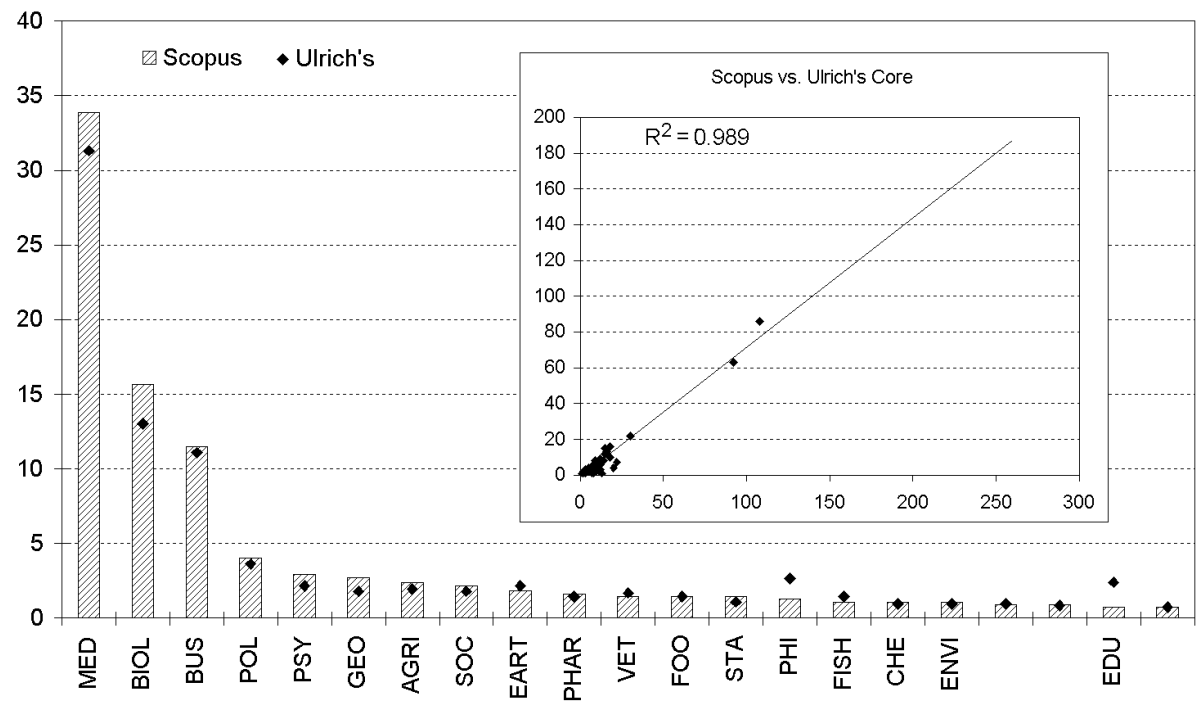

Figure 13. Percentage distribution by subject areas in Ulrich's Core - Blackwell

Table 14. Subject ranking according to the percentage of Scopus journals in Ulrich's Core - Blackwell

\begin{tabular}{llrrrr}
\hline \multicolumn{1}{c}{ Abr. } & \multicolumn{1}{c}{ Subject } & \%Scopus & \% Ulrich & \%S/U & \% Ref S/U \\
\hline GEO & Geography & 2.73 & 1.81 & 100.00 & 100.00 \\
PSY & Psychology & 2.91 & 2.17 & 88.89 & 93.33 \\
AGR & Agriculture & 2.37 & 1.93 & 81.25 & 86.67 \\
SOC & Sociology & 2.19 & 1.81 & 80.00 & 84.62 \\
BIOL & Biology & 15.66 & 13.01 & 79.63 & 89.25 \\
POL & Political Science & 4.01 & 3.61 & 73.33 & 78.57 \\
MED & Medical Sciences & 33.88 & 31.33 & 71.54 & 79.51 \\
BE & Business and Economics & 11.48 & 11.08 & 68.48 & 70.73 \\
ES & Earth Sciences & 1.82 & 2.17 & 55.56 & 56.25 \\
\hline
\end{tabular}




\section{Conclusions}

The results described here allow us to draw a profile of Scopus in terms of its coverage by areas - geographic and thematic - and the significance of peer-review in its publications. Both these aspects are highly pragmatic considerations for the users of scientific databases, and in particular for the authors and the policy makers who rely on database presence as a main criterion for scientific promotion. Our most important findings are:

- Fifteen percent of Scopus journals are published in languages other than English, as opposed to $26 \%$ of Ulrich's Core. This would explain Scopus's greater coverage of scientific output journals with respect to popular science journals, as typically found in the Social Sciences and Arts and Humanities.

- As far as geographical coverage is concerned, parallels can be seen in the distribution of the two collections. Scopus's distribution resembles that of Ulrich's except in the United Kingdom, Netherlands and Germany. The United States is the country with the most journals in Scopus (due to scientific size), with substantial distance from the Ulrich reference. In the U.S. and U.K. on the whole, the subject area distribution is clearly inclined towards Medicine, Biology, Engineering, Psychology and Economics; whereas in Netherlands and Germany a specialisation in the the areas of Computing, Mathematics, Physics and Chemistry is observed.

- The vast majority of publishers (97\%) are over-represented in both collections (Ulrich's Core and Scopus), in contrast with their wide diversity of the two regarding distribution by subject areas, countries and language of publication.

- As far as the main publishers are concerned, Elsevier and Blackwell provide most coverage on a worldwide level and show a fairly even thematic distribution. In Ulrich, Blackwell is better represented than Elsevier. The Springer Verlag stands out in Medicine, Biology, Computing and Psychology, while Taylor \& Francis do so in Chemistry, Medicine, Environmental Studies and Engineering.

- Statistically speaking then, the coverage provided by Scopus is balanced in terms of subject areas, languages and editors when compared with Ulrich's Core. In general we can say that Scopus has quite homogenous global representation in nearly all areas except Arts and Humanities, a fact pointed out in previous studies and shown on the Scopus website. Scopus covers $35 \%$ of Social Science journals worldwide. 
- One of the areas not specifically dealt with in this study but that points us toward future research projects is the analysis of Scopus's temporary coverage trends. We should underline the fact that Scopus is a database with criteria similar to those of Thomson ISI, not only in the development of the collection but also in its coverage on the world level. There are, however, significant differences regarding output and citation. Though Scopus's size is its strength, this is not reflected in citation until the 90's.

To very briefly conclude, and with possible future bibliometric studies in mind, the above considerations conform an important part of the context of scientific output and evaluation, and should be taken into account so as to avoid bias in the comparison of research results in diverse domains or at different aggregation levels.

\section{References}

Archambault, É., Vignola-Gagné, É., Côté, G., Larivière, V., Gingras, Y. (2005), Welcome to the linguistic warp zone: Benchmarking scientific output in the social sciences and humanities. In: INGWERSEN, P., LARSEN, B. (Eds), Proceedings of the 10th International Conference of the International Society for Scientometrics and Informetrics (ISSI). Karolinska University Press, pp. 149-158.

Braun, T., GlänZel, W., Schubert, A. (2000), How Balanced is the Science Citation Index's Journal Coverage? A preliminary Overview of Macrolevel Statistical Data. In: CRONIN, B., ATKINS, H. B. (Eds), The Web of Knowledge - A Festschrift in Honor of Eugene Garfield. Canada: American Society of Information Science, pp. 251-277.

CoDinA, L. (2005), Scopus: el mayor navegador científico de la web, El Profesional de la Información, $14: 44-49$

Deis, L. F., Goodman, D. (2005), Web of Science (2004 version) and Scopus, The Charleston Advisor, 6. Text available at: http://www.charlestonco.com/comp.cfm?id=43

JACSO, P. (2004), Scopus, Péter's Digital Reference Shelf. September 2004. Text available at: http://www.galegroup.com/servlet/HTMLFileServlet?imprint=9999\&region=7\&fileName=reference/archive/ 200409/scopus.html

JACSO, P. (2005), As we may search - Comparison of major features of the Web of Science, Scopus, and Google Scholar citation-based and citation-enhanced databases, Current Science, 89: 1537-1547 Text available at: http://www.ias.ac.in/currsci/nov102005/1537.pdf

LAGUARDIA, C. (2005), E-views and reviews: Scopus vs. Web of Science. Library Journal, 15. Text available at: http://www.libraryjournal.com/index.asp?layout=articlePrint\&articleID=CA491154

SCOPUS FAQs http://www.info.scopus.com/aboutscopus/faqs/index.shtml

SCOPUS Info - List of journals. http://www.info.scopus.com/aboutscopus/documents/title_list.xls

Ulrich's International Periodicals Directory. http://www.ulrichsweb.com 


\section{Appendix}

Table 15. List of Abbreviations for Ulrich's Core Categories (The cells in italics show those categories in Scopus which do not have journals)

\begin{tabular}{|c|c|c|c|}
\hline Abr. & Ulrich's subject & Abr. & Ulrich's subject \\
\hline MED & Medical sciences & INSU & Insurance \\
\hline ENG & Engineering & ASI & Asian studies \\
\hline BUS & Business and economics & LITE & Literature \\
\hline $\mathrm{CHE}$ & Chemistry & FIR & Fire prevention \\
\hline PSY & Psychology & REAL & Real estate \\
\hline PHY & Physics & BIRT & Birth control \\
\hline COMP & Computers & SG & Sports and games \\
\hline MAT & Mathematics & MACHI & Machinery \\
\hline EART & Earth sciences & HPR & Heating plumbing and refrigeration \\
\hline PHAR & Pharmacy and pharmacology & AW & Animal welfare \\
\hline ENV & Environmental studies & LPR & Literary and political reviews \\
\hline AGRI & Agriculture & LR & Leisure and recreation \\
\hline EDU & Education & PHOT & Photography \\
\hline POL & Political science & PAC & Packaging \\
\hline BIOL & Biology & $\mathrm{CT}$ & Clothing trade \\
\hline $\mathrm{SCW}$ & Sciences: comprehensive works & RUB & Rubber \\
\hline GEO & Geography & BEV & Beverages \\
\hline LAW & Law & $\mathrm{HCW}$ & Humanities: comprehensive works \\
\hline SOC & Sociology & $\mathrm{OCCU}$ & Occupations and careers \\
\hline VET & Veterinary science & PBT & Publishing and book trade \\
\hline MET & Metallurgy & ART & Art \\
\hline PHS & Public health and safety & JOUR & Journalism \\
\hline ENE & Energy & APR & Advertising and public relations \\
\hline ND & Nutrition and dietetics & CEP & Consumer education and protection \\
\hline SCCW & Social sciences: comprehensive works & MEN & Men's health \\
\hline GG & Gerontology and geriatrics & $\mathrm{BC}$ & Beauty culture \\
\hline TRAN & Transportation & HOT & Hotels and restaurants \\
\hline ELE & Electronics & LFI & Leather and fur industries \\
\hline LIS & Library and information sciences & TOB & Tobacco \\
\hline FF & Forests and forestry & PRIN & Printing \\
\hline HIS & History & PTC & Patents trademarks and copyrights \\
\hline PET & Petroleum and gas & $\mathrm{CD}$ & Cleaning and dyeing \\
\hline LIN & Linguistics & BIB & Bibliographies \\
\hline COMM & Communications & BIOG & Biography \\
\hline ASF & Aeronautics and space flight & HOB & Hobbies \\
\hline FFI & Food and food industries & HOM & Homosexuality \\
\hline SSW & Social services and welfare & MUS & Music \\
\hline
\end{tabular}


F. DE MOYA-ANEGÓN et al.: Coverage analysis of Scopus

Table 15. (cont.)

\begin{tabular}{|c|c|c|c|}
\hline ANTH & Anthropology & NAS & Native american studies \\
\hline HUP & Housing and urban planning & PO & Parapsychology and occultism \\
\hline DAA & Drug abuse and alcoholism & PHI & Philately \\
\hline HFA & Health facilities and administration & SRR & Sound recording and reproduction \\
\hline METER & Meteorology & $A H$ & Arts and handicrafts \\
\hline AST & Astronomy & $I D D$ & Interior design and decoration \\
\hline STA & Statistics & $M P$ & Motion pictures \\
\hline MMI & Mines and mining industry & $C L U$ & Clubs \\
\hline WR & Water resources & $N E E$ & Needlework \\
\hline PALE & Paleontology & AIS & Abstracting and indexing services \\
\hline OHS & Occupational health and safety & $A N T$ & Antiques \\
\hline PHI & Philosophy & $A S T$ & Astrology \\
\hline TCW & Technology: comprehensive works & $C Y A B S$ & Children and youth_abstracting bibliographies statistics \\
\hline FISH & Fish and fisheries & $C Y$ & Children and youth_for \\
\hline CLE & Criminology and law enforcement & $C D$ & Civil defense \\
\hline PLAS & Plastics & $C L A$ & Classical studies \\
\hline PS & Population studies & $C A$ & College and alumni \\
\hline TIF & Textile industries and fabrics & $D A N$ & Dance \\
\hline CONS & Conservation & $E G A$ & Encyclopedias and general almanacs \\
\hline $\mathrm{BC}$ & Building and construction & FOL & Folklore \\
\hline PA & Public administration & $G H$ & Genealogy and heraldry \\
\hline $\mathrm{AM}$ & Alternative medicine & $G T$ & Giftware and toys \\
\hline CYA & Children and youth_about & $H E$ & Home economics \\
\hline PFH & Physical fitness and hygiene & $H Y$ & How-to and do-it-yourself \\
\hline $\mathrm{ARCH}$ & Archaeology & $J C W$ & Jewelry clocks and watches \\
\hline CERAM & Ceramics glass and pottery & $L U$ & Labor unions \\
\hline HANDI & Handicapped & $L I F$ & Lifestyle \\
\hline WS & Women's studies & MATR & Matrimony \\
\hline $\mathrm{GH}$ & Gardening and horticulture & $M C$ & Meetings and congresses \\
\hline WH & Women's health & $M E I$ & Men's interests \\
\hline INST & Instruments & $M E S$ & Men's studies \\
\hline ARCHIT & Architecture & $M A G$ & Museums and art galleries \\
\hline TT & Travel and tourism & $N A P$ & New age publications \\
\hline REL & Religions and theology & $N U M$ & Numismatics \\
\hline METRO & Metrology and standardization & PETS & Pets \\
\hline MIL & Military & $T H E$ & Theater \\
\hline ETH & Ethnic interests & $W I$ & Women's interests \\
\hline GIP & General interest periodicals & FUN & Funerals \\
\hline PP & Paper and pulp & $S B$ & Shoes and boots \\
\hline PPC & Paints and protective coatings & SIL & Singles' interests and lifestyles \\
\hline
\end{tabular}

